\title{
Sin esencialismos y sin filosofías de la historia. Cómo escapar de lógicas discursivas dominadoras sin emplear el lenguaje de los dominadores
}

\section{Without Essentialisms and without Philosophies of History. How to Escape from Dominant Discursive Logics without Using the same Language as the Dominators}

\author{
Jorge Polo Blanco ${ }^{1}$ \\ Escuela Superior Politécnica del Litoral (Ecuador)
}

Recibido: 20-04-17

Aprobado: 16-07-17

\section{Resumen}

En el presente trabajo intentaremos abordar una problemática crucial para todos aquellos pensamientos latinoamericanos que han pretendido escapar de las lógicas discursivas coloniales y eurocéntricas. Tomando como base las tesis del filósofo colombiano Santiago Castro-Gómez, trazadas en su obra Crítica de la razón latinoamericana, argumentaremos que no se puede combatir la colonialidad eurocéntrica que todavía subyuga a América Latina empleando el mismo lenguaje

\footnotetext{
${ }^{1}$ (hiperbolik1983@hotmail.com). Doctor en Filosofía por la Universidad Complutense de Madrid. Ha publicado múltiples artículos en revistas especializadas, por ejemplo: "Karl Polanyi y la hybris economicista de la Modernidad", Logos. Anales del Seminario de Metafisica, Universidad Complutense de Madrid, Vol. 46, 2013, pp. 261-285; "También explotación, pero no sólo. Un diálogo imprescindible y polémico entre Marx y Karl Polanyi”, Tópicos. Revista de Filosofía, Universidad Panamericana, México, 2015, pp. 81-121; "Economía y biología. La decisiva influencia del naturalismo en la construcción teórica de la Economía Política", Daimon. Revista Internacional de Filosofia, Universidad de Murcia, España, No 69, 2016, pp. 93-108; "Aristóteles descubre la economía, para temerla. Una lectura desde Karl Polanyi”, Signos Filosóficos, Universidad Autónoma Metropolitana, Iztapalapa, México, Vol. XIX, Núm. 37, enero-junio, 2017, pp. 8-37. También ha publicado dos libros: Perfiles posmodernos. Algunas derivas del pensamiento contemporáneo (Dykinson, Madrid, 2010); y La economía tiránica. Sociedad mercantilizada, dictadura financiera y soberanía popular (Carpe Noctem, Madrid, 2015). Actualmente, prepara otro libro sobre la filosofía política de Friedrich Nietzsche.
} 
y las mismas construcciones discursivas a través de las cuales se articuló y materializó ese dominio. Porque, utilizando estos elementos, permaneceríamos anclados o encerrados en la narrativa hegemónica (en la episteme) que Occidente utilizó, precisamente, para dominar a otros pueblos.

Palabras-clave: esencialismo identitario, idealización latinoamericanista, filosofías de la historia, eurocentrismo, colonialidad.

\begin{abstract}
In this paper, we will attempt to address a problematic which is crucial for all those Latin American modes of thinking that have sought to escape from colonial and Eurocentric discursive logics. Using the Colombian philosopher Santiago Castro-Gómez's ideas - outlined in his Critique of Latin American Reason - as our starting point, we will argue that one cannot combat the Eurocentric coloniality which still subjugates Latin America using the same language and the same discursive constructions through which this dominance is articulated and takes shape. This is because by using these components, we would remain bound to or enclosed within the very hegemonic narrative (the episteme) the West used to dominate other peoples.
\end{abstract}

Key-words: identity essentialism, Latin American idealisation, philosophies of history, Eurocentrism, coloniality.

\title{
1. Introducción
}

En las siguientes páginas pretendemos trazar un recorrido que, por razones obvias de espacio, no puede ser exhaustivo o pormenorizado. Somos plenamente conscientes, desde un punto de vista metodológico, de los diferentes contextos (histórico-geográficos, culturales e intelectuales) en los que se producen los textos de los diversos autores que serán analizados. Pero, en cualquier caso, sostendremos que más allá de las irreductibles diferencias podemos descubrir una misma lógica discursiva que subyace en buena parte de dichas propuestas teóricas. Evidentemente, el esencialismo puede decirse de muchos modos, al igual que una filosofía de la historia puede construirse de muy distintas maneras. No es igual, digámoslo ya, la perspectiva ontológico-fenomenológica de Rodolfo Kusch que las tesis de un socialismo amerindio puestas en juego por José Carlos Mariátegui; es más, ambas propuestas habitan universos filosóficos radicalmente distintos, alejados. Tampoco es comparable la filosofía de la historia que encontramos en la obra de Leopoldo Zea con aquella otra que podemos hallar esbozada en las páginas escritas por Carlos Cullen. Pero, 
a pesar de las numerosas diferencias teóricas y políticas que median entre todos estos autores, lo que pretendemos es descubrir en ellos un cierto gesto discursivo que los hace incurrir (con todos los elementos diferenciales que se quiera, que en verdad son muchos y sustanciales) en una misma lógica (esencialista o filosófico-histórica); algo que los convierte (aunque sólo en este respecto) en discursos hasta cierto punto equiparables. Tan es así, que resulta sugestivo e interesante explorar críticamente ese hilo conductor a través de una constelación variada de pensadores latinoamericanos.

\section{Idealizaciones latinoamericanistas}

El escritor uruguayo José Enrique Rodó publicó en 1900 su influyente Ariel. En esta obra se postulaba que las naciones latinoamericanas estaban en cierto modo fascinadas y obnubiladas por los Estados Unidos, tanto sus élites como sus capas populares; es lo que él denominó nordomanía, un término enormemente expresivo (1985: 94). Rodó, al hablar del gran vecino del Norte, y recordemos que estaba recién comenzado el siglo XX, advertía lo siguiente: "La poderosa federación va realizando entre nosotros una suerte de conquista moral. La admiración por su grandeza y por su fuerza es un sentimiento que avanza a grandes pasos en el espíritu de nuestros hombres dirigentes, y aún más, quizá, en el de las muchedumbres, fascinables por la impresión de la victoria. Y de admirarla se pasa por una transición facilísima a imitarla" (1985: 93). Es la concepción utilitaria de la vida, un incombustible y omnipotente pragmatismo, lo que preside y anima el titánico movimiento del gigante norteamericano. "Si ha podido decirse del utilitarismo que es el verbo del espíritu inglés, los Estados Unidos pueden ser considerados la encarnación del verbo utilitario" (Ibíd.). Rodó quería alertar contra lo que él consideraba una deriva cultural muy peligrosa, a saber, una América del Sur cada vez más “deslatinizada” por obra de una poderosísima influencia foránea portadora de algunos valores no del todo deseables (1985: 94-95). Porque esa vorágine intensamente utilitarista, advertía Rodó, sólo podía producir en el largo recorrido "espíritus estrechos" y una "cultura unilateral" (1985: 51). Él, en definitiva, temía que la América hispana perdiese su idiosincrasia más íntima en aras de una emulación acrítica de la América del Norte. El argentino Manuel Ugarte, compartiendo el mismo diagnóstico, escribió en 1901 La defensa latina (1987).

Un cuarto de siglo más tarde, el mexicano José Vasconcelos también advertía que las naciones hispanoamericanas habían sucumbido a "las prédicas desespañolizantes" y al "inglesamiento correlativo" (2001: 11), con todas las consecuencias culturales y espirituales que tal proceso podría llevar a término. En ese sentido, él pretendía ver una pugna (un antagonismo, quizás) 
entre dos cosmovisiones históricamente enfrentadas y disímiles. "Pugna de latinidad contra sajonismo ha llegado a ser, sigue siendo en nuestra época, pugna de instituciones, de propósitos y de ideales" (2001: 6). Y en esa pugna cultural, pensaba Vasconcelos, el espíritu hispano venía perdiendo la batalla desde hacía ya mucho tiempo, como una identidad antaño férrea que ahora iba disolviéndose por efecto de un agente corrosivo exógeno. También el peruano Salazar Bondy, ya a finales de los años sesenta, profundizaría en ese mismo horizonte de sentido, lamentándose de la "inautenticidad" de la filosofía hispanoamericana, precisamente porque ésta se había fundamentado en la pura imitación de modelos que siempre le venían impuestos desde una exterioridad cultural imperial (1988); lo cual, es cierto, tenía que ver con el lugar periférico (dependiente) que las naciones latinoamericanas ocupaban en el sistema económico mundial. En cualquier caso, y las obras de estos autores constituyen la perfecta ejemplificación de ello, el discurso filosófico se ha deslizado en múltiples ocasiones hacia una suerte de idealización latinoamericanista. Se postulaba, en efecto, una "eticidad latinoamericana" no contaminada (esto es, resguardada en su propia mismidad) por el sucio pragmatismo crematístico del Norte Anglosajón y se exaltaban, por ende, los valores intrínsecos del "espíritu latino" (siempre amenazado desde el exterior). Desde luego, esa amenaza siempre fue real (en lo económico-político y en lo cultural); pero en muchos casos tal situación se comprendió y teorizó desde un esquema identitario y esencialista.

También José Carlos Mariátegui ahondó (con otros objetivos y desde otros presupuestos) en ese horizonte, postulando la existencia de una "solidaridad primordial" viva en el interior de las comunidades indígenas, depositarias al parecer de un ethos casi prístino de reciprocidad (no pervertido aún por una racionalidad moderna exógena y basada en el egoísmo competitivo) que habría de servir de base para la construcción de un socialismo específicamente indoamericano (1991). O el chileno Pedro Morandé que, en su Cultura y modernización en América Latina, también sostendría la tesis de que un ethos "postizo" (aquilatado a través de una racionalidad modernizante de estirpe protestante) vino a imponerse al ethos auténtico: una síntesis de lo ibérico, lo negro y lo indígena (1984). Se trataría, en su análisis, de una identidad preiluminista y barroca que siempre habría dejado situada a la América Latina en un lugar ajeno al de la modernidad europea triunfante (que no fue, desde luego, la modernidad hispana). Un ethos diferente, el de los hispanoamericanos, que tal vez debiera ser resguardado (esto es lo que parece insinuarse en la obra de Morandé) para que otros modus vivendi no viniesen a desdibujarlo.

Tales discursos, a pesar de sus notables diferencias teóricas y sus distintos contextos de producción, terminaron por incurrir en una cierta apología del "ensimismamiento cultural" (o en la glorificación de una suerte de aislacionismo 
diferencial), como si América Latina estuviera felizmente condenada a vivir encapsulada en una geografía cultural siempre refractaria (en lo profundo de sí) a esa violenta y avasalladora lógica europea fundamentada en una racionalidad instrumental omnímoda; como si esa América guardara en su interior alguna suerte de identidad prístina, o un ethos insobornablemente distinto, inadaptable en cualquier caso a las crueles veredas por las cuales quisiera conducirla una exterioridad siempre perversa y acechante.

\section{Esencialismos identitarios, retornos a lo auténtico}

Rodolfo Kusch, en su América profunda, quiso analizar lo americano en el sentido de acceder a un mundo más antiguo (más elemental) que perviviría todavía en las entrañas del mundo contemporáneo. Pero postulaba, y he aquí el núcleo de su obra, que tal mundo arcaico sobrevivía como algo esencialmente distinto y aun adverso a las capas civilizatorias que ulteriormente vinieron a superponerse "encima" de aquel substrato primigenio. Aquel elemento "originario" resultaría hoy casi incomprensible, produciría incluso miedo y desagrado, porque no sería subsumible en el orden de cosas actual. Se trataría de un afuera antagónico, otro ritmo de vida que sin embargo latiría en la interioridad de esas capas que el progreso, la técnica y la intelectualización ciudadana habrían ido tejiendo y apelmazando. Sería, pensaba Kusch, una suerte de hálito profundo que aún hoy sobreviviría por detrás de la presuntuosa "pulcritud" occidentalizada y europeizada. Hálito que, por cierto, nos asedia y nos asalta aunque hayamos pretendido dejarlo atrás; estaría ahí, al acecho, nunca desaparecido. Es un sustrato viviente y telúrico, constitutivo, moviéndose por el altiplano, enraizado en el paisaje, anclado en el "atraso" secular, en el fondo de la prehistoria, en todo ese magma vital que se mueve más allá de las ciudades, las banderas oficiales y los próceres de la patria. Lo que se pretendió definitivamente sepultado, en verdad, viviría también en las pupilas de todos esos indios que se agolpan en los villorrios depauperados de las grandes ciudades latinoamericanas. Porque América, había defendido ya en La seducción de la barbarie, se encontraba dramáticamente escindida entre la verdad de fondo de su naturaleza "demoníaca" (una vitalidad primaria anclada en el inconsciente social) y la verdad ficticia e impostada de sus grandes urbes capitalinas (Kusch 1953).

La sabiduría de América radicaría en un impulso profundo, en una actitud vital inmarcesible, que podría ser rastreada y descubierta prospectando las capas de artificiosidad civilizatoria que hoy nos separan de ella. "En verdad esta actitud se encuentra sólo hacia el interior de América, remontando su pasado o bajando hacia las capas más profundas de su pueblo" (Kusch 1999: 
29). Pensaba que podía efectuarse ese descenso hacia las capas basales, que podía realizarse el reencuentro con alguna identidad más verdadera, auténtica o esencial. Establecía, en ese sentido, una abierta dicotomía (al parecer, de carácter ontológico) entre "los estratos profundos de América" y los "progresistas y occidentalizados ciudadanos" (capas socioculturales más recientes, superpuestas). En otro lugar, Kusch postuló una misma contraposición entre los "saberes populares" (existencialmente anclados) y los "saberes enciclopédicos" (institucionalizados artificialmente por las élites urbanas europeizadas, que manejan "ideales educativos" postizos y ajenos a la realidad viva que los rodea); ambas formas de conocer permanecerían divorciadas y en planos inconmensurables (Kusch 1976). Bien es cierto que sostuvo la existencia de un proceso de "fagocitación", por medio del cual sería el sustrato "profundo" el que terminaría por apoderarse del sustrato "superficial" (invirtiendo así el tradicional esquema de "aculturación", que implicaba una destrucción de lo indígena por parte de lo occidental).

En cualquier caso, Kusch parece sostener que ambas fuerzas se han mezclado como el agua y el aceite: esto es, permaneciendo en un estado de incomunicabilidad recíproca, como si ambas realidades permanecieran impermeabilizadas la una con respecto a la otra. "Es cuando tomamos conciencia de que algo nos impide ser totalmente occidentales aunque nos lo propongamos" (1999: 135). Ese algo estaría sitiando o asediando nuestra "desnaturalizada" cáscara civilizatoria; sería una realidad inextinguible que jamás permitiría la occidentalización completa del continente americano. "Es un sustrato que se mantiene ignorado y no se registra sino en el plano folclórico o etnográfico, pero ofrece su resistencia sorda [...] Una de las características de la cultura indígena consiste indudablemente en que debe subyacer a las estructuras republicanas. Y es este sub-yacer o estar debajo lo que la mantiene en estado relativamente puro [...]" (1999: 141). Según Kusch, cabe la posibilidad de volver a reconectar o reenganchar con esa "otra parte" de nosotros mismos que vive de forma escindida y separada en nuestra propia interioridad, constituyéndonos, "porque sólo así volveríamos a tomar esa antigua savia de la que nos han querido separar" (1999: 161). Se estaría manejando aquí, a nuestro modo de ver, una tesis esencialista: existiría una suerte de identidad pura, incontaminada, preexistente y subsistente a la que eventualmente se podría regresar o a la cual se podría de algún modo revivir o reanimar.

Con anterioridad, Ezequiel Martínez Estrada (1997) también había señalado en su Radiografía de la pampa que América Latina vivía escindida y tensionada por dos racionalidades verdaderamente irreconciliables: aquella que emergía como una fuerza mística desde las profundidades de la tierra (potencia telúrica incontenible), y aquella otra que trató de imponerse de forma artificiosa 
a través de códigos, legislaciones e instituciones de aspecto europeo; esto es, postulaba dos identidades antagónicas ocupando (sin poder mezclarse) una misma geografía. Es cierto que Martínez Estrada se movía en las coordenadas teóricas de un cierto romanticismo historicista y, por lo tanto, en un contexto intelectual bien diferente. Pero, en cualquier caso, también podemos observar y descubrir en su obra la puesta en juego de un cierto esencialismo que, como en Kusch, se materializaba en un esquema binario de identidades cerradas y contrapuestas.

Sin duda el libro de Kusch es valioso por mostrar cómo, por ejemplo, la categoría de "lo argentino" se construyó (en lo político y en lo cultural) mirando a Europa y, a su vez, despreciando todos aquellos componentes indígenas o amerindios que se asentaban desde tiempo atrás en lo que luego resultó ser el territorio de la República (llegándose, incluso, al exterminio físico de esas poblaciones). Pero el problema radica en el esquema teórico utilizado; porque, y he aquí la clave de lo que pretendemos mostrar, el pensador argentino asume de forma acrítica (quizás con la mera intención de invertirlo) el sistema binario manejado, precisamente, por la visión eurocéntrica: Occidente (encarnando la racionalidad verdadera y la civilización superior) enfrentado a la otredad no occidental (saberes pre-lógicos y supersticiosos, pura barbarie). Pero tratar de invertir axiológicamente tal esquema (señalando que los "valores auténticos" y los "saberes genuinos" se dan en la otredad no-occidental, mientras que Occidente encarnaría perversamente todo tipo de anti-valores, siendo la pura maldad), hacer esta inversión axiológica, queremos insistir en ello, dejaría intacto el esquema mismo. Y dejar intacto tal esquema significa, desde luego, que la matriz del discurso colonial no se ha extinguido, que permanece su lógica profunda; significa, en suma, que las presuntas críticas así formuladas siguen ancladas en el universo discursivo articulado por el poder colonial.

Las comunidades indígenas y campesinas andinas han aparecido en algunos discursos idealizadas y mistificadas; se construyen relatos que operan como fabulaciones ahistóricas que las presentan como una suerte de entidades puras (supervivencias precolombinas inalteradas) basadas enteramente en principios sociales de reciprocidad y, por lo tanto, como si fuesen comunidades estacionarias y esencialmente "anti-mercado" y "anti-desarrollo" (una retórica que, es verdad, no deja de recordar al mito del "buen salvaje", que popularizara entre otros Jean-Jacques Rousseau). Semejante perspectiva la podemos encontrar en Javier Medina, por poner un ejemplo, toda vez que sostiene que las comunidades amerindias son sociedades básicamente (esencialmente) anti-mercantiles que habrían resistido durante quinientos años, en una suerte de inmaculado reducto geográfico e histórico, los embates de la aculturación desarrollista occidental (2001: 176). Estaríamos ante un ingenuo "primitivismo indigenista” que imagina una otredad esencial (situada en un afuera absoluto 
con respecto a la modernidad occidental); un lugar de pureza donde residen (y resisten) las esencias comunitarias más auténticas (no mancilladas aún).

¿Pero acaso es necesario recurrir al esencialismo identitario, para poder construir un discurso capaz de enfrentarse críticamente con la colonialidad cultural y con el neocolonialismo económico-político? Las primeras críticas sistemáticas al "discurso colonial" han sido datadas en los análisis que Edward Said publicó en 1978, en su ya clásico texto Orientalism. Su mérito consistió en poner de relieve que la maquinaria colonial puramente "material" (económica, política y militar) estaba vinculada íntimamente a formas discursivas y a regímenes de saber que conceptualizaban, codificaban y definían al otro, al colonizado. Toda dominación colonial, por lo tanto, precisa de un aparato discursivo. La construcción que Europa hace de su propia y moderna identidad (y, por lo tanto, buena parte de sus expresiones culturales, artísticas e intelectuales más relevantes) está inextricablemente unida a las imaginaciones, narraciones y proyecciones de "lo exótico", esto es, a una particular percepción y categorización de los-otros-no-europeos (Said 1996 y 2002). Después, y profundizando en esa misma línea, vendrían obras como las de Homi K. Bhabha (2002) o Gayatri C. Spivak (2010).

Pero también debemos retrotraernos a movimientos como el de la négritude, surgido en el París de los años treinta a manos de estudiantes africanos y antillanos oriundos de territorios colonizados y "afrancesados". Frente a las representaciones de lo africano pergeñadas en la blanca metrópoli, el movimiento (que fue también literario) trató de "recuperar" (o construir) una "identidad negra" que había de ser vindicada para, en última instancia, oponerse a todos los discursos racistas que sobre el mundo negro habían construido las potencias colonizadoras (Omar 2008: 71-111). Es cierto, no obstante, que el peligro de recaer en un esencialismo de "lo africano" también estaba latente en ese movimiento, por más que su (loable) intencionalidad fuera la de confrontar con la dominación blanca. Frantz Fanon señaló que lo que estaba en juego en el poder colonial era una ontología sobre-determinada desde fuera de sí misma. "Ya mostraremos cómo lo que se llama el alma negra es una construcción del blanco" (1973: 13). Entendió, en la dolorosa y lacerante autocomprensión de su identidad, que ésta había sido forjada en los imaginarios del colonizador blanco; éste, dice, "me había tejido con mil detalles, anécdotas y relatos" (92). Porque el negro, como ha señalado el camerunés Achille Mbembe, no es en realidad sino un "yacimiento de fantasías urdidas por Occidente" (2016: 83). Una subjetividad desgarrada, producida secularmente en el interior de una matriz cultural radicalmente subalternizada. "El negro no tiene resistencia ontológica a los ojos del blanco" (Fanon 1973: 91). Porque también debe hablarse de una "colonialidad del ser" (Maldonado 2007). Incluso cuando la vanguardia surrealista, aliada con ciertos movimientos políticos revolucionarios, quiso 
denunciar la decadencia asfixiante de la "racionalidad occidental", y para ello pretendió hallar en la exoticidad del "alma negra" una serie de características capaces de llevarnos a un reencuentro con la virginidad de las pulsiones irracionales, estaba contribuyendo (quizás sin pretenderlo) al aquilatamiento de esa dicotomía que reserva para Europa todo lo que tiene que ver con "lo racional", mientras adjudica a "lo africano" todo ese universo de significados vinculados a lo primitivo, lo sensual, lo corporal, lo lúbrico e instintivo. Los surrealistas, finalmente, estaban prolongando (probablemente sin mala fe) los mismos esquemas de la etnología evolucionista decimonónica (Mbembe 2016: 86-90). Quisieron trabajar poéticamente en aras de la liberación, pero cometieron el error de utilizar el mismo lenguaje fabricado por el enemigo.

Porque, en el fondo, la simple inversión conserva la naturalización esencialista de presuntas identidades cerradas (sustancias herméticamente constituidas, congeladas y petrificadas en su inmutabilidad). El antropólogo haitiano Michel-Rolph Trouillot comentaba que esa radical dicotomía entre un "nosotros" (genuino y superior) y un "todos los demás" (perversión siempre amenazante, bárbara) era precisamente el orden simbólico creado por la narrativa totalizante de Occidente; sin embargo, muchas ideologías "tercermundistas" trataron de replicar ese mismo orden poniendo en juego una suerte de imagen refleja invertida (2011b: 75). Corrientes intelectuales que se autoproclaman "críticas de la colonialidad" pero que, al final, son incapaces de pluralizar y descentrar las múltiples otredades, contraponiendo de nuevo identidades esencializadas y entrampándose así en una lógica discursiva propia del pensamiento occidentalocéntrico; lo cual, a juicio de Eduardo Restrepo, es insuficiente conceptual y políticamente, toda vez que una simple reversión de los términos no pulveriza la relación misma (2007: 293).

El propio Enrique Dussel, en su fundante Filosofía de la liberación, obra publicada en 1977, pudo caer en esa ilusión de pretender hallar una realidad socio-cultural completamente al margen de la matriz totalizadora colonial, latiendo por fuera de ella, situada en una exterioridad absoluta (alteridad metafísica) con respecto al sistema mundial de poder. Porque, en dicho esquema, la "periferia" podría convertirse finalmente en una identidad cerrada, en un otro absolutizado y homogeneizado, sin fisuras ni hibridaciones múltiples; recayendo en la ilusión, por lo demás, de que tal otredad así hipostasiada pudiera llegar a erigirse en un sujeto unificado de resistencia. Arturo Escobar, al respecto de esta polémica por la "exterioridad", señalaba: "De ninguna manera esta exterioridad debe ser pensada como un puro afuera intocado por lo moderno. La noción de exterioridad no implica un afuera ontológico, sino que refiere a un afuera que es precisamente constituido como diferencia por el discurso hegemónico. Esta noción de exterioridad surge principalmente por el pensamiento sobre el Otro desde la perspectiva ética y epistemológica de la filosofía de la liberación: el 
Otro como oprimido, como mujer, como racialmente marcado, como excluido, como pobre, como naturaleza [...] Esta interpelación del Otro viene como un desafío ético desde afuera o más allá del marco institucional y normativo del sistema" (2003: 63). Pero ese legítimo esfuerzo por rescatar las voces secularmente machacadas y silenciadas (con el afán de restituir la dignidad de todos aquellos mundos criminalmente subalternizados), que es el principio ético en el cual se sustenta toda liberación, puede sin embargo deslizarse hacia una metafísica dualista cristalizada en un proyecto como el siguiente: una liberación iniciada desde un lugar absolutamente exterior a la totalidad dominante.

En este discurso de Dussel, como bien señala Santiago Castro-Gómez, la heterogénea multiplicidad de los oprimidos quedaría fijada o inscrita en un sujeto liberador postulado como monolítico y homogéneo; esto es, dichas identidades oprimidas aparecerían integradas y subsumidas en una identidad omnicomprensiva o "metacomprensiva" (1996: 74). Pero, entonces, por vía de tal subsunción (pretendidamente liberadora) volvería a ejercerse sobre las identidades oprimidas y subalternas una nueva violencia estranguladora y homogeneizadora incapaz de reconocer su autónoma singularidad. Y, además, la propuesta de Dussel conllevaría un cierto esencialismo, que se expresa en los siguientes términos: "Las clases oprimidas o populares de las naciones dependientes son las que guardan en su cultura propia la máxima exterioridad del sistema actual mundial; ellas pueden presentar una alternativa real y nueva a la humanidad futura, dada su metafísica alteridad" (1980: 90). Pudiera ser esto último nada más que una concesión retórica a la hipérbole, pero en realidad tal discurso encierra una concepción en la cual la emancipación procederá de un lugar completamente exterior a la totalización del poder mundial; siendo así que, además, esa misma exterioridad confiere a las "periferias oprimidas" la calidad de depositarias de un ethos compuesto por valores completamente ajenos (y moralmente superiores) a los valores predominantes en el universo perverso de los "centros opresores". Se estarían poniendo en juego, por lo tanto, dos vectores: una absoluta exterioridad (que, a su vez, implicaría subsumir los múltiples "sujetos" oprimidos en un mismo sujeto omnicomprensivo) y al mismo tiempo (o precisamente por efecto de tal posición "exterior") una pureza moral superior en todos los sentidos. Una vez más, nos hallaríamos ante una estructura de pensamiento idéntica a la trazada por el canon eurocéntrico-colonial, por mucho que dicha estructura pretenda "invertirse" con fines liberadores.

El chileno Cristian Parker, con su obra Otra lógica en América Latina, también intentó mostrar que la mentalidad popular latinoamericana opera con una lógica diferente (y tal vez opuesta) a la proyectada por la modernidad occidental. América Latina sería lo otro de la Modernidad, pues en ella podría descubrirse una realidad anterior (y éticamente superior, gracias precisamente 
a esa "anterioridad") al logos europeo (1993). Un esquema que también se había expresado en la obra de Juan Carlos Scannone, ya que éste postulaba la pervivencia de una "racionalidad ética y simbólica" (la propia de la geografía cultural y espiritual latinoamericana, la que mana desde el fondo de su mismidad) que, además, constituiría una suerte de reserva axiológica capaz de enfrentarse al dominio de esa "racionalidad instrumental" (preñada de pura voluntad de poder) procedente de una "modernidad" foránea y perversa (1990). Se reproduce y replica el esquema binario, una vez más.

Michel Foucault contribuyó de forma muy significativa a impugnar toda concepción racionalista, teleológica o metafísica de la historia humana. La genealogía nos enseñaba, en efecto, que al retirar todas las máscaras y al disolver todas las capas superpuestas que recubren nuestras más venerables "verdades" de tipo noseológico y moral encontramos no una esencia pura por fin desvelada; no una prístina y eterna identidad replegada en su propia quietud y plenamente adecuada a sí misma; muy lejos de ello, lo que mostraría el "método genealógico" es que tras las máscaras no se esconde ninguna esencia pura, ninguna identidad inmutable. En la raíz de lo que conocemos y de lo que somos no hay un "ser verdadero" que permanezca inalterado bajo el tráfago caótico de lo desordenado y lo aparente, de igual modo que en la historia no hay coherencias últimas o sentidos finales. Sólo hay equilibrios precarios y sentidos parciales, construidos por unas voluntades de poder que puede ser más o menos fuertes. Lo que nos espera tras descorrer trabajosamente los velos es, sencillamente, la constatación de que no existe nada parecido a una esencia; nada parecido a una identidad absoluta. En el origen de las cosas más sagradas no hay solemnidad; la epifanía de lo eterno queda completamente desactivada. Simplemente, cuando ponemos en marcha el trabajo genealógico, descubrimos los tramos en absoluto lineales por los que ha pasado la compleja y heterogénea cristalización de un cúmulo de elementos que sólo la coacción de la historia (expresada en las múltiples violencias del poder) ha convertido en algo aparentemente inalterable (Foucault 2014).

Castro-Gómez, manejando esa perspectiva foucaultiana, señala que muchos de los discursos que hemos examinado incurren en esa obsesión por hallar un fundamento último, una "identidad latinoamericana profunda" que acaso permita distinguir lo auténtico de lo espurio; que permita, de igual modo, imaginar un "nosotros" homogéneo capaz de confrontar con la modernidad occidental desde una posición de absoluta exterioridad. Discursos, por cierto, no exentos de un cierto mesianismo anclado en una "nostalgia por los orígenes" (CastroGómez 1996: 94-97). Pero en verdad no es necesario emplear discursos de factura esencialista para combatir el eurocentrismo. Y la impugnación de tales discursos no nos deja inermes desde un punto de vista crítico, sino más bien todo lo contrario: no emplearlos implica no sucumbir al orden moderno y europeo 
del saber. "Los «discursos de identidad» son generados, entonces, a partir de prácticas institucionales de control y dominio que producen narrativamente al otro como un todo homogéneo. Por ello, rechazar estas prácticas colonialistas no significa apelar a una supuesta «autenticidad cultural» del sujeto colonizado, pues este tipo de idealizaciones recaen en el mismo sustancialismo logocéntrico que se quiere superar" (Castro-Gómez 1996: 146). Las teorías que pretenden ser críticas con la colonialidad del poder y del saber no pueden construirse a través de los mismos mecanismos discursivos que siempre empleó el discurso colonial.

\section{Construyendo otra filosofía de la historia, usando el lenguaje de los dominadores}

Todas las civilizaciones humanas no europeas, según estipula la hermenéutica del tiempo histórico hegemónica en la modernidad occidental, son "periferia" con respecto a Europa, que aparece como el "centro" de la Historia Mundial. Aníbal Quijano lo focalizó con precisión cuando señalaba que "los europeos generaron una nueva perspectiva temporal de la historia y re-ubicaron a los pueblos colonizados, y a sus respectivas historias y culturas, en el pasado de una trayectoria histórica cuya culminación era Europa" (2000: 210). En este esquema evolucionista y monológico, que representa el "mito fundacional" del etnocentrismo occidental (Quijano 2000: 220), y que sólo aparentemente habría quedado superado, la racionalidad emerge como un producto exclusivamente europeo, toda vez que sólo Europa habría logrado salir de ese lamentable y primitivo estado de naturaleza en el que se hallarían sumidas la práctica totalidad de las vastas regiones no-europeas. El poder colonial operaba con dispositivos de racialización y subalternización, pero hizo algo más con respecto a todos esos pueblos: los re-ubicó en el pasado (mejor dicho, en su pasado, el de Europa). La superioridad cultural y racial de los colonizadores se fundamentaba, precisamente, en esa matriz temporal. Y así se articuló de forma hegemónica (en el imaginario moderno-colonial) lo que Quijano denominó "perspectiva histórica dualista/evolucionista" (2000: 225), un poderoso constructo según el cual todos los pueblos no-europeos pudieron ser considerados como pre-europeos (operación discursiva determinante) y, al mismo tiempo, fueron introducidos en cierta cadena temporal (secuencia evolutiva unilineal) que "avanzaba" (y sólo podía hacerlo atravesando unas "fases" concretas y unos "estadios" específicos) desde lo primitivo a lo civilizado, de lo irracional a lo racional, de lo tradicional a lo moderno, de lo mágico-mítico a lo científico. El tiempo siempre jugaría a favor de la europeización; el transcurso evolutivo de cualquier pueblo incivilizado siempre avanzaría, irremediablemente, en esa dirección. 
Ya en 1957 el mexicano Leopoldo Zea denunció el trasfondo etnocéntrico que latía en esas "filosofías de la historia" que habían proliferado durante la Ilustración y habían terminado cristalizado decimonónicamente en sistemas como el de Comte (1970: 37-58); tales discursos brindaban una perfecta justificación teórica e ideológica de la preeminencia cultural de un Occidente que se expandía militar y económicamente por todo el mundo. Un constructo teórico dentro del cual sólo Europa se deslizaba por el eje temporal del progreso histórico, y en el que por tanto sólo ella aparecía como protagonista activa de la Historia Universal, quedando los pueblos no-europeos expulsados de la verdadera historia y sumidos en un dominio de pura negatividad representado por la "quietud" de la barbarie y la animalidad. "Filosofías de la historia dentro de las cuales todo el pasado no es otra cosa que simple abono para el florecimiento de la cultura occidental [...] Florecimiento infinito de la cultura occidental en línea siempre ascendente" (Zea 1970: 42). Sin embargo, como veremos después, el propio Zea quiso oponerse a dicho dispositivo con las mismas herramientas, esto es, construyendo una filosofía histórica de la conciencia americana.

En el interior de esta poderosa y envolvente construcción filosóficotemporal, todos esos territorios humanos no-europeos (no-occidentales) fueron ubicados en una anterioridad que era pensada e imaginada como incompleta, carente e inferior; sociedades, en suma, que habían de ser mejoradas o superadas, esto es, traídas al presente. La categoría de lo "anacrónico" adquiría connotaciones odiosas y despreciables. Es lo que Castro-Gómez denominaba "la no simultaneidad temporal entre las sociedades indígenas americanas y las sociedades ilustradas europeas" (2005: 37). Esa filosofía, expresada nítidamente en pensadores ilustrados como Turgot, concebía que ambas sociedades coexistían en el espacio pero no en el tiempo. El vector-tiempo, el eje inexorable por el cual transcurría el progreso objetivo del espíritu humano, determinaba que aquellas comunidades humanas habitaban un "tiempo anterior", en lo referente a su organización material y despliegue espiritual; mientras que las sociedades europeas habitaban un "tiempo presente", esto es, un tiempo avanzado y por ello mismo intrínsecamente superior.

Recordaba Walter Mignolo cómo Max Weber apuntaló su noción de "progresiva racionalización" del universo cultural y espiritual europeo, aseverando que éste fue el único en haber logrado alcanzar un estatus de genuino y verdadero conocimiento. "Weber nunca mencionó el colonialismo, desconocía la diferencia colonial y nunca reflexionó sobre el hecho de que estaba proponiendo semejante escenario celebratorio en el momento más álgido de la expansión europea y de la acumulación de capital en la historia del sistema-mundo moderno/colonial" (2003: 61). El "occidentalismo", en tanto que imaginario articulador de ese sistema-mundo, operó como 
"una poderosa máquina de subalternización del conocimiento (desde los primeros misioneros del Renacimiento hasta los filósofos de la Ilustración), estableciendo simultáneamente un modelo epistemológico planetario" (Mignolo 2003: 122). Cuando en 1784 Kant estableció en Was ist Aufklärung? que gran parte de la humanidad permanecía en un estado ignominioso de inmadurez y embrutecimiento, perseverando en una suerte de "minoría de edad autoculpable", sobreentendía que sólo ciertos europeos habían podido acceder a la luz del verdadero conocimiento, lo que a su vez significaba que los "otros conocimientos" no eran tales (Dussel 1995: 68). Todo lo cual implicaría, en última instancia, una categorización jerárquica de los saberes y un drástico criterio de demarcación para sepultar múltiples conocimientos en el área de lo "ingenuo", lo "supersticioso" y lo "atrasado". Pero, en cualquier caso, lo que ahora deseamos recalcar es que todos estos juegos de poder basados en la jerarquización-subalternización están enmarcados y subsumidos en esa matriz temporal de la que hablábamos hace un momento.

Recordemos, a modo de epítome de toda filosofía eurocéntrica, aquel tremendo veredicto de Hegel (recogido en sus Lecciones dictadas en la cátedra de Berlín en 1830) según el cual América era un continente que, hasta el momento, no había ingresado en el despliegue racional de la Historia Universal, permaneciendo de ese modo en una región temporal de estática oscuridad, en los márgenes de la verdadera historia de la humanidad (1970: 110). Las culturas precolombinas, antes de que los europeos llevasen consigo el espíritu racional de la verdadera historia, aparecían como "fenómenos" apenas diferenciados de la naturaleza y carentes, por ello, de espíritu (Hegel 1970: 105). De ese modo, y como bien señaló el historiador y filósofo argentino Arturo Andrés Roig, las tierras americanas aparecían ante los ojos de Hegel como una suerte de materia prima maleable a la que había que otorgar forma desde fuera; América era un gigantesco pedazo de naturaleza al margen de la Historia, y sólo Europa podía insuflarle espíritu racional (Roig 1981: 126). Y es así, en definitiva, que "las historias locales europeas han sido proyectadas en diseños globales" (Mignolo 2003: 77), configurando eso que Trouillot llamó "universales noratlánticos" (2011a). El "discurso del poder" afianzado en el interior del sistema-mundo moderno, y anclado en una economía-mundo capitalista absolutamente eurocentrada, se fundamentó en un oxímoron muy eficaz, a saber, el "universalismo europeo". Un discurso secularmente reproducido y modulado, desde la "misión evangelizadora" del siglo XVI hasta la "labor civilizatoria" del siglo XIX, alcanzando finalmente los "programas desarrollistas" del siglo XX (Wallerstein 2007).

Los europeos, por lo tanto, se imaginaron a sí mismos como siendo lo más avanzado de la especie humana. Pero si hay algo que aparece como avanzado es porque, de manera inmediatamente correlativa, algo permanece en estado 
atrasado. Y este sistema binario constituido por lo avanzado/atrasado (o cualquier otro binomio de categorías análogas) opera en un plano geopolítico y geoeconómico, como bien supo diagnosticar la Teoría de la Dependencia; pero opera también en un plano geocultural, pues tales categorizaciones producen subjetividad e intersubjetividad. Esto es, los habitantes de los pueblos dominados interiorizan (y, por lo tanto, naturalizan) su propia posición subalterna. $\mathrm{Y}$ este paradigma, que efectivamente ha sido nombrado como "occidentalismo" (Coronil 1996), se ha tornado hegemónico incluso para los habitantes de las regiones así llamadas "periféricas". El canon europeo y moderno de racionalidad se transforma, y es éste un aspecto ínsito a la estrategia colonizadora, en la única episteme válida a la hora de organizar todos los elementos de la vida; y lo que va quedando por fuera de sus parámetros se concibe como doxa supersticiosa que debe ser paulatinamente desechada (Castro-Gómez 2005).

Chakrabarty, sintetizando el núcleo teórico del grupo de Estudios Subalternos fundado por Ranajit Guha, apuntaba que todos los relatos acaban confluyendo en un torrente histórico europeo que, por supuesto, aparece como el caudal principal de la Historia Universal: "La proposición que alegaré es más perversa. Consiste en que, en lo concerniente al discurso académico sobre la historia [...] «Europa» sigue siendo el sujeto teórico soberano de todas las historias, incluyendo las que denominamos «india», «china», «keniata», etcétera. De un modo peculiar, todas estas historias propenden a convertirse en variaciones de un relato maestro que cabría denominar «la historia de Europa». En este sentido, la propia historia «india» se encuentra en una posición subalterna; en nombre de esta historia sólo es posible articular posiciones de sujeto subalternas" (2008: 57). Las narrativas históricas periféricas, subyugadas, no alcanzan un estatus autónomo, toda vez que aparecen como meros capítulos o apéndices del "gran relato" europeo. Como señalaba el propio Guha, debe realizare "una re-escritura que escuche las voces bajas de la historia" (2002: 30 ), esto es, que propicie una polifonía en la que resuenen con nitidez todas aquellas voces que siempre resultaron inaudibles en la historiografía estandarizada y hegemónica. Porque la escritura de la historia casi siempre ha revelado, en efecto, una jerarquización que determina aquello que debe ser escuchado (por ser considerado primordial, determinante y relevante) y aquello que sin embargo debe permanecer en silencio (por ser juzgado secundario, intrascendente e irrelevante). La colonialidad, en consecuencia, produce una determinada figuración de la experiencia temporal. O, dicho de otra manera, existe también una colonialidad de las narrativas históricas.

Chakrabarty, profundizando en este asunto, advertía que la expresión "historia de las minorías" ha servido para que una historiografía más democrática restituya todas esas omisiones y exclusiones que pueden 
detectarse en las grandes narrativas estandarizadas. Pero advierte, no obstante, que la noción de "minoría" no es una realidad estadística, sino una construcción semántica atravesada por relaciones de poder. Existen numerosísimos ejemplos de situaciones en las que grupos (socioeconómicos o étnico-culturales) cuantitativamente inferiores han aparecido investidos de una suprema autoridad (espiritual, moral y racional) que los convertía, a la postre, en los únicos sujetos de la verdadera historia; en esos casos, por lo tanto, los numéricamente mayoritarios terminaban siendo esas "minorías" subalternas a las cuales la historiografía hegemónica apenas otorgaba voz o agencia propias (Chakrabarty 1999). En definitiva, y como señalaba Boaventura de Sousa Santos desde su "sociología de las ausencias", ese silenciamiento ha de ser activamente producido. "La no-existencia es producida siempre que una cierta entidad es descalificada y considerada invisible, no-inteligible o desechable. No hay por eso una sola manera de producir ausencia, sino varias. Lo que las une es una misma racionalidad monocultural" (2011: 30). Porque lo subalterno y lo silente deben ser permanentemente construidos como tales.

También Edmund Husserl, abundando en esa matriz teórica, consideraba que Europa encarnaba una suerte de destino histórico que rebasaba toda otra particularidad cultural; argüía que en Europa existía algo singular y único, toda vez que los otros grupos humanos, a pesar de mostrar una voluntad evidente de autoconservación espiritual, experimentaban finalmente una incitación a "europeizarse", en tanto que los europeos conscientes de sí jamás optarían por "indianizarse" (1990: 329). Según Husserl, la figura espiritual de Europa representa la cristalización histórica de un telos verdaderamente racional y universal que sólo se desplegó en el seno de esta civilización. Por ello, la civilización europea aparecía a sus ojos como cualitativamente distinta a cualquier otra idiosincrasia cultural, rebasando toda cosmovisión local o "indígena". Ante semejante epifanía, los pueblos que fueron entrando en la órbita de este espíritu europeo no pudieron sino sumergirse en un proceso inexorable de europeización. Y, en efecto, así fue. Pero lo que habría que dilucidar, evidentemente, es qué quiso decir exactamente Husserl cuando hablaba de una suerte de "incitación" a europeizarse; porque, tal vez, esa figura espiritual europea (poseedora, al parecer, de una cualidad harto singular que la diferenciaría beatíficamente de todas las demás civilizaciones humanas) no sea, en realidad, sino un conjunto de relaciones de dominio criminalmente ensambladas.

Discursos como el de Hegel o Husserl (y los de tantos otros) se articulan en el interior de un patrón de poder colonial, como ha reiterado Enrique Dussel en múltiples ocasiones. "De acuerdo con este paradigma, Europa poseía características internas excepcionales que le permitieron superar, a través de su racionalidad, a todas las demás culturas" (1999: 147). Europa, dentro de 
semejante esquema, se habría desarrollado de forma auto-referencial, en un despliegue lineal y autopoiético que se expresó en la consagrada secuencia Renacimiento-Reforma-Ilustración-Revolución francesa.Perotal periodización, recalca Dussel, es mitológica. Porque esa modernidad europea, lejos de ser el fruto endógeno de un desarrollo independiente e interno, solamente llegó a ser lo que finalmente fue en íntima relación con múltiples exterioridades; porque lo que comúnmente (bajo el amparo hegemónico del canon eurocéntrico) se ha denominado "modernidad" no es sino la cultura propia del centro del «sistema-mundo», aquel primer sistema-mundo forjado y articulado con la incorporación de Amerindia. Pero no hay "centro" sin "periferia". Esto es, no hay modernidad (definida por Dussel como la "administración" reproductiva de la posición central) sin colonialidad. Modernidad y colonialidad, y es ésta su tesis fuerte, son dos nociones mutuamente correlativas. O dicho de otra forma: a la modernidad Europea le son inherentes el colonialismo (económico-político y militar) y la colonialidad (epistémica, lingüística, simbólica y discursiva). Esta crítica de Dussel es muy útil para desmontar la matriz filosófico-temporal que ha sustentado durante siglos el dominio colonial; sin embargo, como ya vimos en el epígrafe anterior, él mismo recayó (aunque sólo en algunas partes de su obra) en esquemas teóricos parcialmente esencialistas (que, como ya hemos señalado con abundancia, también formaron parte del discurso colonial).

Pero es cierto, y es ahí a donde queríamos llegar, que el discurso filosófico latinoamericano se ha deslizado en muchas ocasiones hacia formas que terminaron por constituir una suerte de filosofía de la historia latinoamericana. El propio Leopoldo Zea ha tratado, en ese sentido, de reconstruir las distintas fases por las cuales la "conciencia americana" ha ido trascurriendo hasta alcanzar una plena "autoconciencia" (1976a). La primera etapa en ese "despliegue" tendría que ver con el despertar del largo sueño colonial, cuando los hijos de España nacidos en América tomaron una primera conciencia de su entorno y comenzaron a desear más autonomía política; es ahí cuando la "conciencia latinoamericana" (pues ella es el sujeto de tal movimiento históricoespiritual) desemboca libertariamente en la emancipación política. Pero una vez alcanzada tal independencia, afloraron las nuevas limitaciones inherentes a tal momento dialéctico; los criollos ilustrados pensaron ingenuamente que la libertad emergería espontáneamente, y que bastaba con imitar las instituciones de Europa y Estados Unidos. Pero no fue así, y la "conciencia americana" hubo de transitar hacia un nuevo momento basado en la comprensión de que era imprescindible practicar una emancipación cultural (más profunda que la mera independencia política); es entonces cuando la "conciencia americana" (como sujeto colectivo) percibe la perentoria necesidad de superar de una vez por todas la herencia espiritual española, y por ello se hace positivista (Sarmiento, Alberdi, Bello, Lastarria, etc.), toda vez que los elementos que compondrán el 
porvenir ya no se buscarán en un pasado (español y amerindio) que debe ser definitivamente superado (Zea 1976a: 68). Pero, poco tiempo después, también se revelarían las profundas limitaciones de ese segundo "momento", pues tal proyecto se encontró con las limitaciones ineluctables de querer emprender un proceso modernizador que trataba de avanzar sin la incorporación (la asunción) de un pasado que todavía estaba ahí, vivo. Es en ese momento cuando la "conciencia americana" alcanza la tercera fase en su despliegue hacia el conocimiento de sí: el anterior positivismo es rechazado, y el pensamiento latinoamericano vuelve los ojos hacia su propia historia, valorando su propia identidad y no renegando de su herencia (Rodó, Martí, Vasconcelos etc.). El punto de partida, ahora, será el "espíritu latino" propio de "Nuestra América" (Zea 1976a: 424). Pero el despliegue de la conciencia americana, para culminar el largo y tortuoso camino hacia la conciencia de sí, debería aún avanzar un poco más, hasta alcanzar una forma de pensamiento como aquella que se encarnó en las figuras de Salazar Bondy, Cardoso, Freire, Dussel y tantos otros. Zea pretendió combatir la filosofía de la historia eurocéntrica construyendo otra filosofía de la historia, esta vez americana. Sin embargo, lo que nunca cuestionó es la pertinencia misma de emplear tal estructura de pensamiento.

Algo muy parecido podríamos hallar en Arturo Roig (al que anteriormente citábamos cuando, precisamente, criticaba a Hegel por dejar a América fuera de la Historia Universal), pues en su Teoría y crítica del pensamiento latinoamericano pretende describir las fases formativas por las cuales ha ido transitado el "sujeto latinoamericano" (unívoco y monolítico), adquiriendo progresiva y dialécticamente conciencia de sí y siendo capaz, finalmente, de pronunciar un "nosotros, los latinoamericanos". También Carlos Cullen, en su Fenomenología de la crisis moral, quiso describir el itinerario atravesado por la conciencia popular latinoamericana hasta alcanzar el conocimiento de sí (1978). El peligro de tales esquemas es que al tratarse de un proceso dialéctico, aquéllos que se ponen a sí mismos como valiosos (esto es, como sujetos protagónicos de la historia que han adquirido plena autoconciencia y anhelan, por ello mismo, quebrar las cadenas de su alienación), pueden impedir en ese movimiento de despliegue a otros "sujetos": negros, mujeres, indígenas, otras sexualidades. La enunciación de un "nosotros" monolítico y omniabarcante, a pesar de sus probables intenciones liberadoras, podría seguir reproduciendo otras relaciones de dominio a través de un silenciamiento de determinadas voces.

En esos metarrelatos homogeneizadores, como los de Zea o Roig, no hay lugar para las múltiples "historias pequeñas", subsumidas de nuevo (con renovadas dosis de violencia epistémica) en otra gran Historia (por mucho que ésta sea propiamente latinoamericana, y no ya eurocéntrica); porque esas pequeñas historias carecerían de significación y de valor, ya que en nada contribuirían al despliegue de ese "sujeto latinoamericano". Detrás de ese mítico sujeto (cuya conciencia se habría desplegado a través de los siglos) hay 
otras luchas de poder, sometimientos microscópicos, relaciones de dominio ocultadas, mecanismos de exclusión inenarrables, voces silenciadas. Esa dialéctica evolución de un sujeto único esconde, en verdad, múltiples grietas, desvíos, fracturas, imposiciones, heterogeneidades inasumibles. Castro-Gómez señala, incluso, que ese "sujeto latinoamericano" opera como una "máscara totalizante" (1996: 117) que invisibiliza a otros muchos sujetos que no han sido investidos de protagonismo en el gran relato. Todo habría sido un proceso histórico de aprendizaje, en esa "dialéctica de la conciencia americana" (Zea 1976b), pero queda por saber dónde se reflejan las voces de las víctimas de ese progresivo y doliente aprendizaje.

\section{A modo de conclusión}

El habla de la dominación tiene serias dificultades para convertirse en un habla de liberación; y ese registro que denominamos "filosofía de la historia", eminentemente europeo-moderno-colonial, difícilmente se convertirá en una gramática emancipadora. La estrategia crítica debiera pasar, más bien, por una "provincialización de Europa", usando el término puesto en juego por Chakrabarty (2000), antes que por un repliegue identitario de corte esencialista o por la construcción de una filosofía de la historia latinoamericana. Porque hipostasiar la propia identidad, aunque fuere para contraponerla de forma defensiva a la identidad forjada por los dominadores, mantendría la estructura binaria construida precisamente por éstos. Con tal proceder, se habría sucumbido a la lógica profunda con la cual el pensamiento colonial objetivó a los pueblos subyugados; se estaría empleando una misma estructura discursiva. Pero provincializar Europa, además, contribuiría a quebrar aquel poderosísimo espejismo por medio del cual los europeos se pensaban e imaginaban a sí mismos como siendo los verdaderos sujetos de la Historia, esto es, los únicos escribientes del relato universal de la especie humana. No se trata, por lo tanto, de construir una "filosofía de la historia americana" (o, si se quiere, latino, hispano o iberoamericana); de lo que se trata, más bien, es de quebrar la lógica misma de dicho constructo. Y quebrar esa lógica dialéctica de la comprensión histórica, desactivando toda narración teleológica (ya sea ésta eurocéntrica o "latinoamericanocéntrica"), no significa que debamos hundirnos en un marasmo de sinsentido. Muy al contrario, se trata de rescatar del olvido aquel conjunto amplísimo de historias que fueron silenciadas por las narrativas hegemónicas, descolonizando múltiples memorias colectivas que quedaron sepultadas $\mathrm{u}$ olvidadas por la violencia epistémica de una Historia, la europea, escrita con hache mayúscula. Cepillando la historia a contrapelo, por emplear la expresión de Walter Benjamin, no para construir otra filosofía de la historia que trate de 
contraponerse a la eurocéntrica, sino para otorgar voz a todas las víctimas que jamás ocuparon un lugar visible y protagónico en el relato oficial escrito por los vencedores y por los verdugos.

¿Significa esto que debemos postular una suerte de revolución sin sujeto? No, porque la batalla contrahegemónica siempre necesita aglutinar (articular) fuerzas en alguna suerte de "identidad política colectiva"; pero esto no implica que tal articulación deba cristalizar en un sujeto único, monolítico y homogéneo que eclipse la heterogeneidad y la hibridez de las voces subyugadas y subalternizadas. El abigarrado mosaico de las múltiples masacres no debe quedar integrado en un mismo relato unificado; los inmensos dramas (jalonados de dominaciones y subyugaciones) que han compuesto la textura de las historias humanas no deben quedar subsumidos (o diluidos) en un mismo despliegue teleológico saturado de sentido. Tras ese marasmo de dolores particulares no puede aprehenderse una racionalidad inmanente que constituya el fin último de la Historia. Lo fáctico no puede convierte de inmediato en racional, como de hecho ocurría en la filosofía de la historia hegeliana, porque en tal meganarración permanecerían sepultados multitud de aconteceres que, habiendo sido, quedarían empero racionalizados (esto es, justificados) y enterrados en el silencio de lo insignificante; porque los vencidos y los masacrados no pueden emerger con digna presencia y con voz propia en el relato oficial de una historia presidida (protagonizada) por un sujeto único, por muy liberador que se autoconciba dicho sujeto. 


\section{Referencias bibliográficas:}

Bhabha, Homi K. (2002). El lugar de la cultura. Buenos Aires: Manantial.

Castro-Gómez, Santiago. (1996). Crítica de la razón latinoamericana. Barcelona: Puvill.

Castro-Gómez, Santiago. (2005). La hybris del punto cero. Ciencia, raza e ilustración en la Nueva Granada (1750-1816). Bogotá: Editorial Pontificia Universidad Javeriana.

Chakrabarty, Dipesh. (1999). "Historia de las minorías, pasados subalternos". Historia y Grafía, México, Año 6, № 12: 87-111.

Chakrabarty, Dipesh. (2000). Provincializning Europe. Postcolonial Thought and Historical Difference. Princeton: Princeton University Press.

Chakrabarty, Dipesh. (2008). Al margen de Europa. Pensamiento poscolonial y diferencia histórica. Barcelona: Tusquets.

Coronil, Fernando. (1996). "Beyond Occidentalism: Toward Nonimperial Geohistorical Categories". Cultural Anthropology, Vol. 11, № 1, February: 51-87.

Cullen, Carlos. (1978). Fenomenología de la crisis moral. Sabiduría de la experiencia de los pueblos. Buenos Aires: Castañeda.

Dussel, Enrique. (1980). Filosofía de la liberación. Bogotá: Universidad Santo Tomás.

Dussel, Enrique. (1995). “Eurocentrism and Modernity”. En The Postmodernism Debate in Latin America, John Beverley, Michael Aronna y Jose Oviedo (Ed.), 65-76. Durham: Duke University Press.

Dussel, Enrique. (1999). "Más allá del eurocentrismo: el sistema-mundo y los límites de la Modernidad". En Pensar (en) los intersticios. Teoría y práctica de la crítica poscolonial, Santiago Castro-Gómez, Óscar Guardiola-Rivera, Carmen Millán de Benavides (Ed.), 147-161. Bogotá: Instituto Pensar, Centro Editorial Javeriano.

Escobar, Arturo. (2003). "Mundos y conocimientos de otro modo. El programa de investigación de modernidad/colonialidad latinoamericano". Tabula Rasa, Bogotá, $\left.\mathrm{N}\right|^{\circ} 1$, enero-diciembre, 51-86.

Fanon, Frantz. (1973). Piel negra, máscaras blancas. Buenos Aires: Abraxas.

Foucault, Michel. (2014). Nietzsche, la genealogía, la historia. Valencia: PreTextos.

Guha, Ranahit. (2002). Las voces de la historia y otros estudios subalternos. Barcelona: Crítica.

Hegel, Georg Wilhelm Friedrich. (1970). Lecciones sobre la filosofía de la historia universal. Barcelona: Zeus.

Husserl, Edmund. (1990). La crisis de las ciencias europeas y la fenomenología transcendental. Barcelona: Crítica. 
Kusch, Rodolfo. (1953). La seducción de la barbarie. Análisis herético de un continente mestizo. Buenos Aires: Raigal.

Kusch, Rodolfo. (1976). Geocultura del hombre americano. Buenos Aires: García Cambeiro.

Kusch, Rodolfo. (1999). América profunda. Buenos Aires: Biblos.

Maldonado, Nelson. (2007). "Sobre la colonialidad del ser. Contribuciones al desarrollo de un concepto". En El giro decolonial. Reflexiones para una diversidad epistémica más allá del capitalismo global, editado por Santiago Castro-Gómez y Ramón Grosfogel, 127-168. Bogotá: Pensar.

Mariátegui, José Carlos. (1991). "El problema de las razas en América Latina". En Textos básicos, edición de Aníbal Quijano, 210-257. México: Fondo de Cultura Económica.

Martínez Estrada, Ezequiel. (1997). Radiografía de la Pampa. Madrid: ALLCA XX.

Mbembe, Joseph-Achille. (2016). Crítica de la razón negra. Ensayo sobre el racismo contemporáneo. Buenos Aires: Futuro Anterior.

Medina, Javier. (2001). Suma Qamaña. La comprensión indígena de la Vida Buena. La Paz: GTZ-PADEP.

Mignolo, Walter. (2003). Historias locales, diseños globales. Colonialidad, conocimientos subalternos y pensamiento fronterizo. Madrid: Akal.

Morandé, Pedro. (1984). Cultura y modernización en América Latina. Ensayo sociológico acerca de la crisis del desarrollismo y de su superación. Chile: Pontificia Universidad Católica, Instituto de Sociología.

Omar, Sidi Mohamed. (2008). Los estudios post-coloniales. Una introducción crítica. Castellón de la Plana, España: Universitat Jaume I.

Parker, Cristian. (1993). Otra lógica en América Latina. Religión popular y modernización capitalista. México y Chile: Fondo de Cultura Económica.

Quijano, Aníbal. (2000). "Colonialidad del poder, eurocentrismo y América Latina”. En La colonialidad del saber: eurocentrismo y ciencias sociales. Perspectivas latinoamericanas, compilado por Edgardo Lander, 201-246. Buenos Aires: CLACSO.

Restrepo, Eduardo.(2007). “Antropología y colonialidad”. En El giro decolonial. Reflexiones para una diversidad epistémica más allá del capitalismo global, Santiago Castro-Gómez y Ramón Grosfoguel (Compiladores), 289-304. Bogotá: Siglo del Hombre Editores; Universidad Central, Instituto de Estudios Sociales Contemporáneos y Pontificia Universidad Javeriana, Instituto Pensar.

Rodó, José Enrique. (1985). Ariel. Madrid: Alba.

Roig, Arturo Andrés. (1981). Teoría y crítica del pensamiento latinoamericano. México: Fondo de Cultura Económica. 
Said, Edward. (1996). Cultura e imperialismo. Barcelona: Anagrama.

Said, Edward. (2002). Orientalismo. Madrid: Debate.

Salazar Bondy, Augusto. (1988) ¿Existe una filosofía de nuestra América? México: Siglo XXI.

Santos, Boaventura de Sousa. (2011). "Epistemologías del sur". Utopía y Praxis Latinoamericana. Revista internacional de filosofía iberoamericana $y$ teoría social, Universidad del Zulia, Año 16. № 54, julio-septiembre: 1739.

Scannone, Juan Carlos. (1990). Nuevo punto de partida de la filosofía latinoamericana. Buenos Aires: Guadalupe.

Spivak, Gayatri Chakravorty. (2010). Crítica de la razón poscolonial. Hacia una historia del presente evanescente. Madrid: Akal.

Trouillot, Michel-Rolph. (2011a). "Moderno de otro modo. Lecciones caribeñas desde el lugar del salvaje”. Tabula Rasa, Bogotá, No 14, enero-junio: 7997.

Trouillot, Michel-Rolph. (2011b). Transformaciones globales. La antropología y el mundo moderno. Cauca-Bogotá: Universidad del Cauca y CESOUniversidad de los Andes.

Ugarte, Manuel. (1987). La nación latinoamericana. Caracas: Biblioteca Ayacucho.

Vasconcelos, José. (2001). La raza cósmica. México: Porrúa.

Wallerstein, Immanuel. (2007). Universalismo europeo. El discurso del poder. México: Siglo XXI.

Zea, Leopoldo. (1970). América en la historia. Madrid: Ediciones de la Revista de Occidente.

Zea, Leopoldo. (1976a). El pensamiento latinoamericano. Barcelona: Ariel.

Zea, Leopoldo. (1976b). Dialéctica de la conciencia americana. México: Alianza Editorial Mexicana. 
